\title{
Effects of Selenium Enrichment of Tomato Plants on Ripe Fruit Metabolism and Composition
}

B. Pezzarossa ${ }^{1, \mathrm{a}}$, I. Rosellini $^{1}$, F. Malorgio ${ }^{2}$, E. Borghesi $^{2}$ and P. Tonutti ${ }^{3}$

${ }_{1}^{1}$ CNR, Istituto per lo Studio degli Ecosistemi, Pisa, Italy

${ }_{3}^{2}$ Dipartimento di Biologia delle Piante Agrarie, University of Pisa, Italy

${ }^{3}$ Scuola Superiore Sant'Anna, Pisa, Italy

Keywords: Solanum lycopersicon, selenate, fruit composition, secondary metabolism, carotenoids, flavonoids

\begin{abstract}
The effects of selenium (Se) addition on production and quality traits of Solanum lycopersicon 'Red Bunch' were investigated. Se was added as sodium

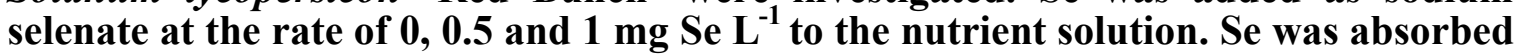
by roots and accumulated in leaves and fruits, and at the tested concentrations, it did not affect yield. Se concentration followed a gradient, decreasing from the basal to the apical part of the plant. At red ripe stage, the fruits on the lower trusses accumulated higher amount of Se than the fruits of the higher trusses. B-carotene

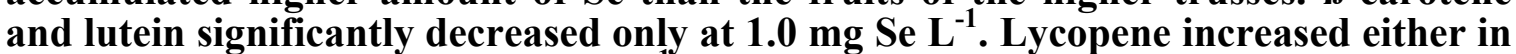
0.5 and, less markedly, $1.0 \mathrm{mg} \mathrm{Se} \mathrm{L}^{-1}$-treated fruits where a pronounced increase in quercetin was also observed.
\end{abstract}

\section{INTRODUCTION}

Selenium (Se) is an essential trace element, a natural antioxidant and an effective anticarcinogenic agent both in humans and animals (Rotruck, 1973; Pallud et al., 1997; Ramauge et al., 1996). In plants, the essentiality of Se as a micronutrient has not been conclusively demonstrated, however it is believed that Se could delay plant senescence and decrease postharvest losses (Hartikainen et al., 2000; Xue et al., 2001). In tomato, Se is effective in reducing the plant growth and in delaying the onset of plant senescence and fruit ripening (Pezzarossa et al., 1999). Considering the effects of Se on secondary metabolism, Lee et al. (2007) found a variable effect on lycopene content in tomato fruit depending on the concentration of Se. In lettuce and chicory, Se has been shown to be effective in decreasing the production of ethylene and PAL activity, consequently improving the quality of leafy vegetables and the shelf life in both species (Malorgio et al., 2009). This paper reports the compositional parameters of ripe fruit of Solanum lycopersicon 'Red Bunch' (cherry tomato) due to Se-enrichment of the nutrient solution.

\section{MATERIALS AND METHODS}

The experiment was conducted in a temperature-controlled glasshouse located in Pisa, Italy (lat. $\left.43^{\circ} 40^{\prime} \mathrm{N}\right)$.

The plants (Solanum lycopersicon 'Red Bunch') were hydroponically grown during the spring-summer season, April 10-July 28, 2009. The minimum temperature and ventilation air temperature inside the glasshouse were 13 and $27^{\circ} \mathrm{C}$, respectively; the maximum temperature was $30-32^{\circ} \mathrm{C}$. The maximum photosynthetic photon flux density (PPFD) ranged from 600 to $800 \mu \mathrm{mol} \mathrm{m}^{-2} \mathrm{~s}^{-1}$; the mean value of daily global radiation (R) was $8.4 \mathrm{MJ} \mathrm{m}^{-2}$.

Seedlings were transplanted 50 days after sowing into $1-\mathrm{m}$ long rockwool slabs. The plants were grown vertically with a single stem at a density of three plants $\mathrm{m}^{-2}$ and pollination was favoured by mechanical vibration of the flower clusters.

Drip irrigation was carried out using a nutrient solution with electrical conductivity (EC) $3.5 \mathrm{dS} \mathrm{m}^{-1}$ and $\mathrm{pH}$ 6.5. Exhaust nutrient solution was discharged after three weeks or whenever the $\mathrm{EC}$ was higher than $6 \mathrm{dS} \mathrm{m} \mathrm{m}^{-1}$. The composition of the

a beatrice.pezzarossa@ise.cnr.it 
nutrient solution was as follows (concentration are expressed in $\mathrm{mmol} \mathrm{L}^{-1}$ ): $12 \mathrm{~N}^{-\mathrm{NO}_{3}}{ }_{3}$,

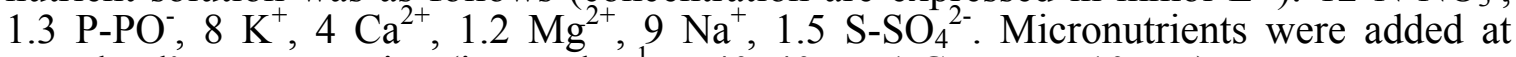
Hoagland's concentration (in $\mu \mathrm{mol} \mathrm{L}{ }^{-1}$ : B 40, $40 \mathrm{Fe}, 1 \mathrm{Cu}, 5 \mathrm{Zn}, 10 \mathrm{Mn}$ ).

Sodium selenate was added at the rate of $0,0.5$ and $1 \mathrm{mg} \mathrm{Se} \mathrm{L}^{-1}$ to the nutrient solution four weeks after transplanting. A second addition of sodium selenate at the same rate was performed after three weeks. When the solution containing selenium ran out, the tank was replenished with nutrient solution.

Tomatoes were harvested at red ripe stage when the soluble solid content was on average $4.6^{\circ} \mathrm{Brix}$ and titratable acidity on average $0.65 \%$. Ten tomato fruits were homogenized and dried at $75^{\circ} \mathrm{C}$ for $72 \mathrm{~h}$ to determine the dry weight. Carotenoid (lutein, lycopene, $\beta$-carotene) extraction was performed according to the method reported by Giuntini et al. (2005) partially modified. The extraction of flavonoids (quercetin, naringenin, rutin) was carried out according to Crozier et al. (1997). The measurements of carotenoids and flavonoids were carried out by HPLC (Jasco, Tokyo, Japan) consisting of a low pressure gradient pump with four solvent model PU-2089 UV-Vis detector and a multichannel UV-2077. The metabolites were identified based on retention times and quantified using calibration curves with pure standards of known concentration.

Total selenium content was determined at harvest in oven-dried ground leaves and fruit samples after digestion with nitric and perchloric acids and reduction by hydrochloric acid, following Zasoski and Burau (1977). The digests were analyzed by hydride generation atomic absorption spectrophotometry (Varian VGA 77).

The experimental design was completely randomized. Data were subjected to one way analysis of variance (ANOVA). The means were separated using the Least Significant Difference (LSD) test for $\mathrm{p} \leq 0.05$ or $\mathrm{p} \leq 0.01$.

\section{RESULTS AND DISCUSSION}

The selenium added to the nutrient solution was absorbed by roots and accumulated in fruits. The higher the amount of Se added, the higher the amount of Se accumulated in fruits (Fig. 1). Selenium concentration, expressed on a dry weight basis, was higher in leaves (data not shown) than in fruits, and followed a gradient, decreasing from the basal to the apical part of the plant. In fact, fruits of the lower trusses accumulated higher amount of Se than fruits of higher trusses (Fig. 1).

Fruit yield was not statistically influenced by selenium addition, as well as the percentage of dry matter content.

Selenium addition influenced the carotenoid concentration in fruits at harvest. Lycopene was higher in the treated samples, particularly at $0.5 \mathrm{mg} \mathrm{Se} \mathrm{L}^{-1}$ (Fig. 2), whereas $\beta$-carotene and lutein contents significantly decreased when Se was added at 1 but not at $0.5 \mathrm{mg} \mathrm{L}^{-1}$ (Fig. 3).

Lee et al. (2007) found an increase of selenium content in tomato fruit of 'Super momotaro' plants grown in nutrient solution added with $0.5,1$ and $2 \mathrm{mg} \mathrm{Se} \mathrm{L}^{-1}$ and only in correspondence of the highest Se concentration lycopene increased in ripe fruit tissues.

The addition of selenium, either at 0.5 or $1 \mathrm{mg} \mathrm{Se} \mathrm{L}^{-1}$, decreased the content of naringenin in fruits, whereas the highest dose of selenium induced a dramatic increase in the quercetin concentration (Fig. 4). The content of rutin was not influenced by the selenium addition (data not shown).

Our data indicate that Se accumulating in tomato may affect fruit secondary metabolism and composition at ripening. The significant decrease of $\beta$-carotene and the slight increase in lycopene in the $1 \mathrm{mg} \mathrm{Se} \mathrm{L}^{-1}$ treatment would indicate that the carotenoid biosynthetic pathway is affected by Se. Sams et al. (2011) reported that, in Arabidopsis, a treatment with Se down regulates the expression of phytoene synthase, a key step in the carotenoid biosynthesis. However, in tomato fruit, other carotenoid genes and enzymes (e.g., lycopene cyclases, responsible for the formation of carotene and lutein from lycopene) may be affected by Se and, most likely, differently by the different concentrations of Se applied, as demonstrated by the effects of Se at $0.5 \mathrm{mg} \mathrm{L}^{-1}$ (Figs. 2 and 3) and the results reported by Lee et al. (2007) on tomato fruit lycopene content. 
Hartikainen et al. (2000) reported that, depending on the dosage, Se exerted dual effects on ryegrass. At low concentrations it acted as antioxidant and stimulated plant growth, whereas at higher concentrations it acted as pro-oxidant, thereby reducing the yield. The significantly higher content of quercetin detected in fruit at 1 but not at $0.5 \mathrm{mg} \mathrm{L}^{-1}$ reinforces the hypothesis of a concentration effect on specific secondary metabolic pathways. Quercetin is a flavonol which has an important role as antioxidant. In addition, they possess anti-viral, anti-microbial, anti-inflammatory and anti-allergic potential that can be expressed on different cell types, both in animal and human models. As an antioxidant, quercetin seems to be the most powerful flavonoid for protecting against reactive oxygen species, produced during the normal oxygen metabolism or induced by exogenous damage. The increase in quercetin content in $1 \mathrm{mg} \mathrm{Se} \mathrm{L}^{-1}$-treated tomatoes may suggest that at this concentration, but not at $0.5 \mathrm{mg} \mathrm{L}^{-1}$, Se, acting as pro-oxidant, activates the antioxidant mechanisms.

\section{Literature Cited}

Crozier, A., Lean, M.E.J., McDonald, M.S. and Black, C. 1997. Quantitative analysis of the flavonoid content of commercial tomatoes, onions, lettuce, celery. J. Agri. Food Chem. 45:590-595.

Giuntini, D., Graziani, G., Lercari, B., Fogliano, V. and Soldatini, G.F. 2005. Changes in carotenoid and ascorbic acid contents in fruit of different tomato genotypes related to the depletion of UV-B radiation. J. Agri. Food Chem. 53:3174-3181.

Hartikainen, H., Xue, T. and Pironen, V. 2000. Selenium as an antioxidant and prooxidant in ryegrass. Plant Soil 225:193-200.

Lee, G.J., Kang, B.K., Kim, T.I., Kim, T.J. and Kim, J.H. 2007. Effects of different selenium concentrations of the nutrient solution on the growth and quality of tomato fruit in hydroponics. Acta Hort. 761:443-448.

Malorgio, F., Diaz, K., Ferrante, A., Mensuali, A. and Pezzarossa, B. 2009. Effects of selenium addition on minimally processed leafy vegetables grown in floating system. J. Agri. Food Chem. 2243-2251.

Pallud, S., Lennon, A.M., Ramauge, M., Gavaret, J.M., Croteau, W., Pierre, M., Courtin, F. and St Germain, D.L. 1997. Expression of the type II iodothyronine deiodinase in cultured rat astrocytes is selenium-dependent. J. Biol. Chem. 272:18104-18110.

Pezzarossa, B., Malorgio, F. and Tonutti, P. 1999. Effects of selenium uptake by tomato plants on senescense, fruit ripening and ethylene evolution. p.275-276. In: A.K. Kanellis, C. Chang, H. Klee, A.B. Bleecker, J.C. Pech and D. Grierson (eds.), Biology and Biotechnology of the Plant Hormone Ethylene II. Kluwer Academic Publishers, Dordrecht, Netherlands.

Ramauge, M., Pallud, S., Esfandiari, A., Gavaret, J., Lennon, A., Pierre, M. and Courtin, F. 1996. Evidence the type III iodothyronine deiodinase in rat astrocyte is a selenoprotein. Endocrinology 137:3021-3025.

Rotruck, J.T., Pope, A.H., Ganther, H.E., Swanson, A.B., Hafeman, D.G. and Hoekstra, W.G. 1973. Selenium: biochemical role as a component of glutathione peroxidase. Science 179:588-590.

Sams, C.E., Panthee, D.R., Charron, C.S., Kospell, D.A. and Yuan, J.S. 2011. Selenium regulates gene expression for glucosinolate and carotenoid biosynthesis in Arabidopsis. J. Amer. Soc. Hort. Sci. 136:23-34.

Xue, T., Hartikainen, H. and Piironen, V. 2001. Antioxidative and growth-promoting effect of selenium on senescing lettuce. Plant Soil 237:55-61.

Zasoski, R.J. and Burau, R.G. 1977. A rapid nitric perchloric acid digestion method for multi-elements tissue analysis. Comm. Soil Sci. Plant Anal. 8(5):425-436. 


\section{Figures}

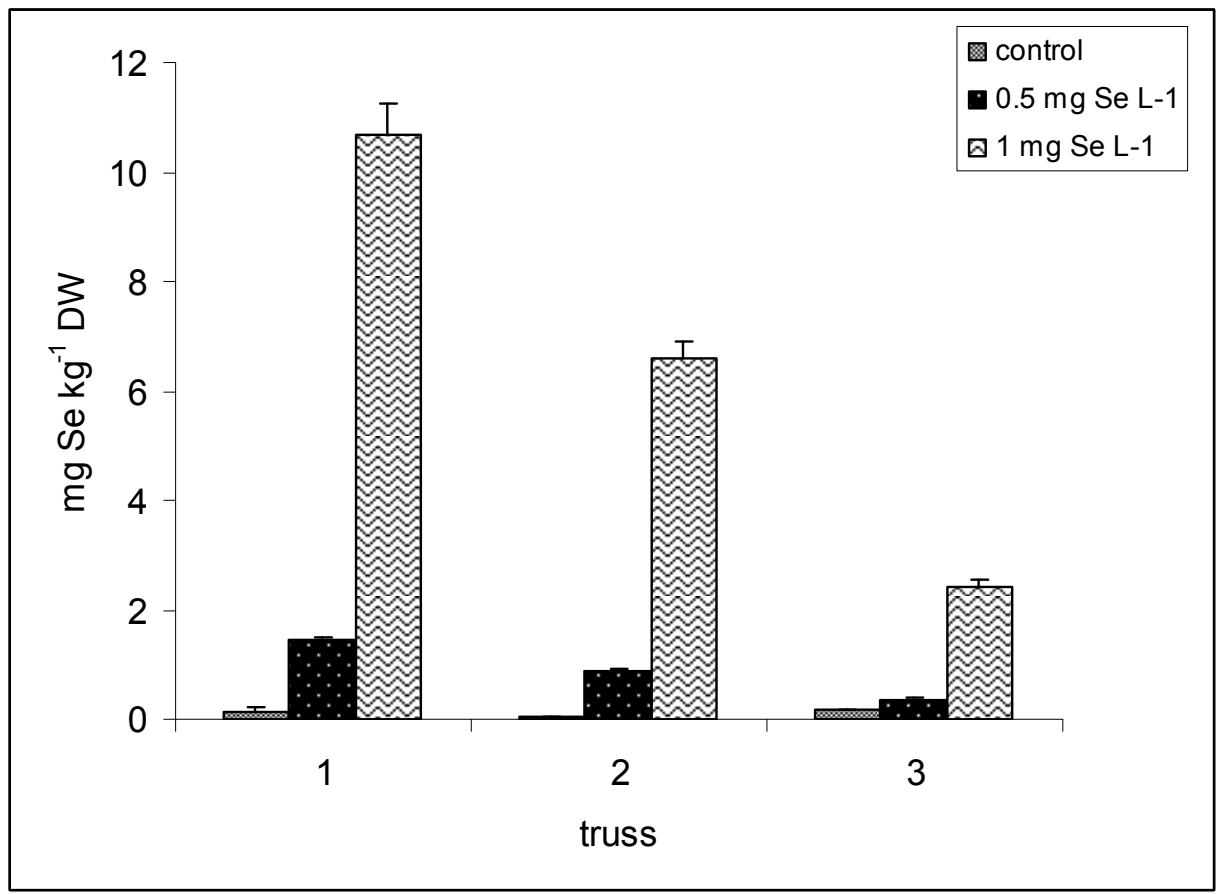

Fig. 1. Selenium concentration measured at harvest in tomato fruit of different trusses of plants subjected to different Se treatments. Data are means $\pm S E ; n=3$.

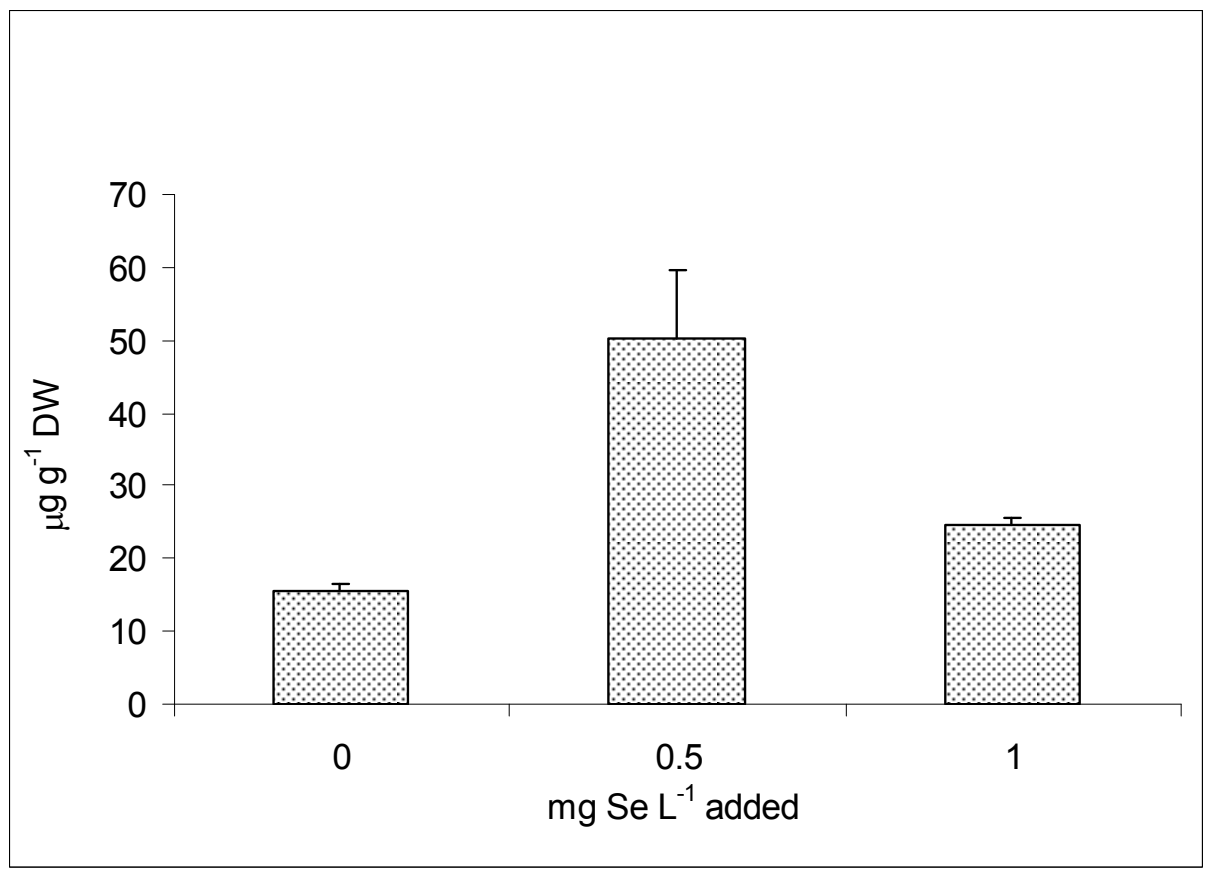

Fig. 2. Lycopene content $\left(\mu \mathrm{g} \mathrm{g}^{-1} \mathrm{DW}\right)$ measured at harvest in tomato fruit of plants subjected to different Se treatments. Data are means $\pm S E ; n=3$. 


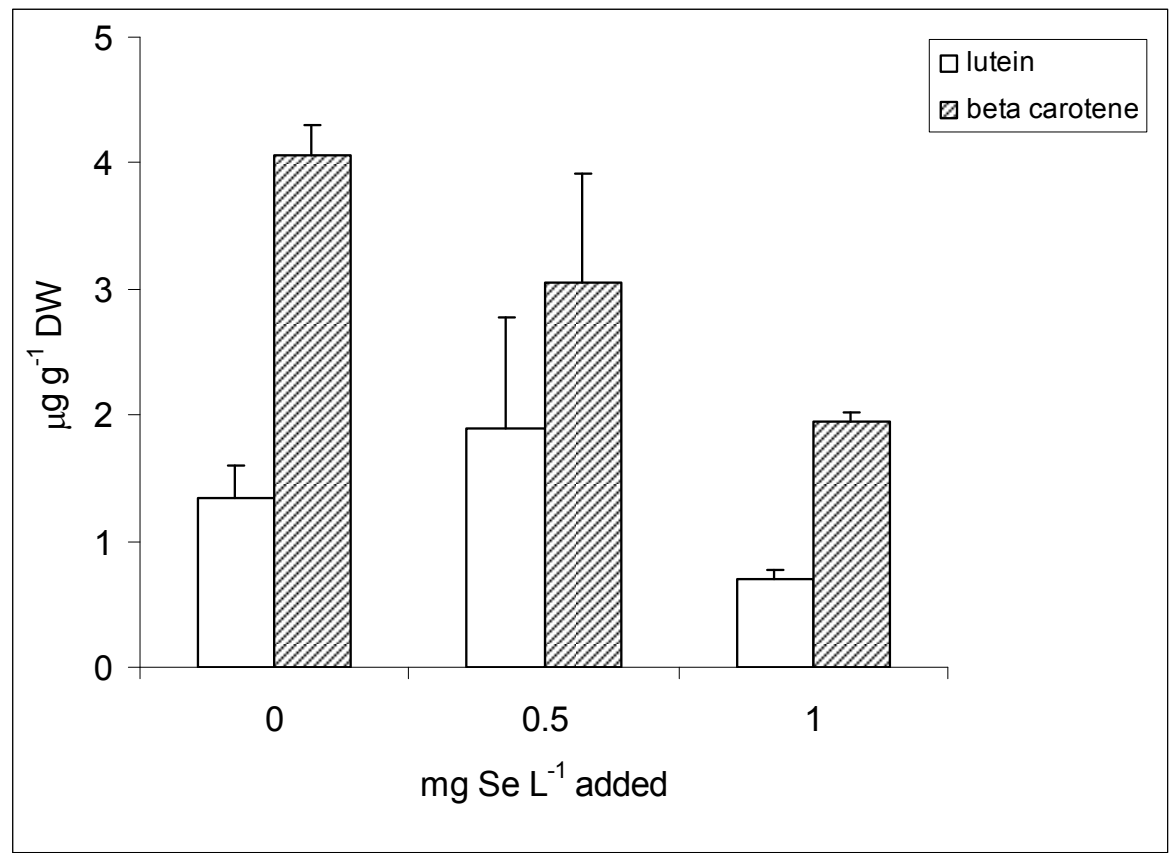

Fig. 3. Lutein and beta-carotene content measured at harvest in tomato fruit of plants subjected to different Se treatments. Data are means $\pm S E ; n=3$.

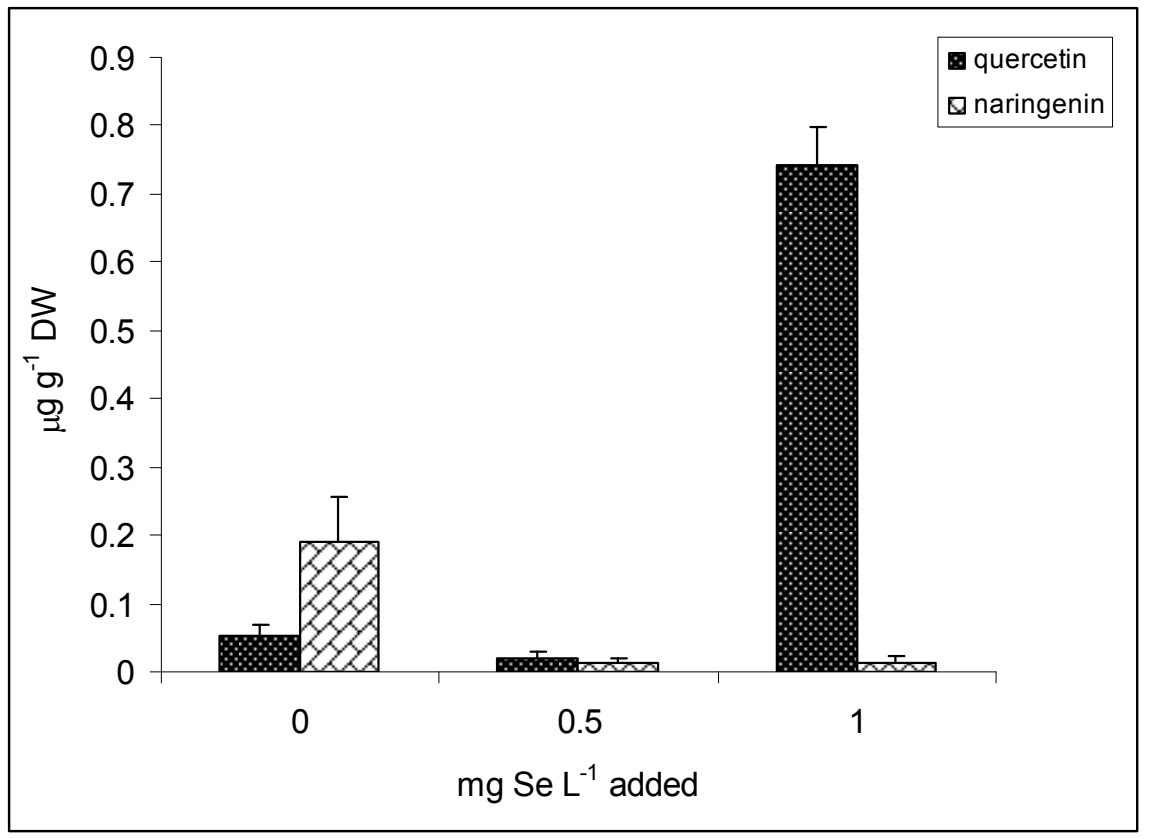

Fig. 4. Quercetin and naringenin contents measured at harvest in tomato fruit of plants subjected to different Se treatments. Data are means $\pm S E ; n=3$. 
